\title{
Personal Growth in Adults' Stories of Life Transitions
}

\author{
Jack J. Bauer \\ Northern Arizona University \\ Dan P. McAdams \\ Northwestern University
}

\begin{abstract}
This study identified four themes of personal growth (integrative, intrinsic, agentic, and communal) in adults' stories of life transitions in careers and religions. Specific themes were expected to relate differentially to two forms of personality development (socialcognitive maturity and social-emotional well-being) and to transition satisfaction. Integrative themes correlated primarily with social-cognitive maturity (ego development; Loevinger, 1976), whereas intrinsic themes correlated primarily with social-emotional well-being. Agentic-growth themes correlated primarily with transition satisfaction, whereas communal-growth themes correlated primarily with global well-being. Themes of agentic and communal growth also differentiated the two types of transitions studied - changes in careers and changes in religions-in ways that both supported and contradicted traditional notions of those transitions. We discuss these findings in terms of narrative meaning making, the mature and happy person, and intentional self-development via life transitions.
\end{abstract}

This paper explores how stories of life transitions relate to personality development. Life transitions represent periods of heightened self-

Jack J. Bauer, Northern Arizona University, and Dan P. McAdams, The Foley Center for the Study of Lives, Northwestern University.

The authors would like to thank the Foley Family Foundation for its major support of this research, the Positive Psychology Summer Training Institute for its support, and April Sakaeda for her insights and work on this project.

Correspondence concerning this article should be sent to Jack Bauer, Department of Psychology, Northern Arizona University, Flagstaff, AZ 86011. Email: jack.bauer@, nau.edu.

Journal of Personality 72:3, June 2004.

Blackwell Publishing 2004 
reflection, attempts at meaning making (Cantor \& Kihlstrom, 1987), and opportunities for development (Bauer \& Bonanno, 2001a). Yet not all life transitions - not even the voluntary ones-leave the individual with a strengthened sense of meaning or happiness in life. We argue that such developments depend in part upon how one interprets the transition. Research has shown that personal interpretations of life transitions have implications not only for the course of the transition but also for the individual's personality and life course more broadly (Brandtstadter, Wentura, \& Rothermund, 1999; McAdams, Josselson, \& Lieblich, 2001). We propose that people who interpret their life transitions in terms of growth will have higher levels of not only satisfaction with the transition but also personality development more generally. Furthermore, we propose that different kinds of growth-oriented interpretations correspond to different kinds of personality development.

In the present study we examined people's stories of two kinds of transitions: changes from one career to another career and changes from one religion to another religion. In these stories we looked for themes that emphasized specific kinds of personal growth - what we called "growth themes." We viewed personal growth in general as a kind of growth that involves the intentional development of one's own personality and life course (i.e., intentional self-development; Brandtstadter et al., 1999; Lerner \& Walls, 1999). We compared themes of personal growth with measures of personality development. ${ }^{1}$ We identified four growth themes: integrative, intrinsic,

1. While the terms "personal growth" and "personality development" are closely related, we reserve "personal growth" for growth that the individual intends and "personality development" for any growth that happens in the individual's personality (e.g., moving to higher levels of ego development or well-being). For the purposes of this article, personal growth can be viewed as a subset of personality development. However, not all forms of personal growth involve personality directly, as in the intentional development of a specific skill. While an individual might hold the development of that skill as an "identity goal" (Gollwitzer, Bayer, Scherer, \& Seifert, 1999), thereby bringing the skill into the domain of personality, the skill itself may also be viewed and studied from nonpersonality perspectives, such as cognitive development, while still falling in the domain of personal growth. Personality development becomes "personal" when the individual intends it, when the individual places importance on that kind of development. Most forms of human development are probably unintentional, that is, they unfold without the explicit purpose of that kind of development, yet some aspects of personality development are intentional and cannot be accounted 
agentic, and communal. The first two growth themes (integrative and intrinsic) dealt with two broad dimensions of personality development, respectively: social-cognitive maturity and social-emotional well-being. The second two growth themes (agentic and communal growth) dealt with differences between transition satisfaction specifically and well-being globally. Agentic- and communal-growth themes also dealt with differences between two groups of people in the study: career changers and religion changers. Finally, all themes of personal growth were considered in an exploration of how mature, happy people interpreted their transitions.

\section{Themes of Integrative and Intrinsic Growth}

The constructs of integrative themes and intrinsic themes in this study arose from theory and research in two approaches to personality development. Studies of personality development typically target one of two broad trajectories: social-cognitive and socialemotional development (Bauer \& McAdams, 2004). Theories of social-cognitive personality development ground their teleology in notions of heightened capacities for mature thinking, complexity of meaning making, differentiation and integration, assimilation and accommodation - in general, how complexly one thinks about the self and others (e.g., Damon \& Hart, 1988; Vygotsky, 1978). Theories of social-emotional personality development ground their teleology in notions of heightened capacities for psychological health, adjustment, happiness, and well-being - in general, how good one feels about the self in a world of others (e.g., Freud, 1953; Greenberg \& Mitchell, 1983). ${ }^{2}$ Common sense suggests that

for by impersonal biological and social forces (Lerner \& Walls, 1999). Such intentions (and their value orientations) can be discerned in narratives of people's self-defining goals and self-defining memories. In this way, narrative measures of personal growth can be compared with assessments of personality development (e.g., ego development and well-being).

2. By "social-cognitive" and "social-emotional," we do not mean to imply that social-cognitive and social-emotional functions are entirely distinct. Furthermore, while social-cognitive developmentalists generally identify themselves as such (e.g., Damon \& Hart, 1988), most of the theorists and researchers we are labeling "social-emotional" developmentalists would not necessarily call themselves that. Our criterion for these designations boiled down to a teleological question: Is the developmental theory primarily directed toward an increase in (1) how complexly the individual thinks about the self and others or (2) how good the individual feels 
maturity and happiness should go hand in hand, much as in Western philosophy's coupling of virtue and happiness (Flanagan, 1991). However, empirical psychology suggests otherwise: Measures of social-cognitive maturity (notably ego development; Loevinger, 1976) typically do not correlate with global measures of psychological health and well-being (e.g., Bauer \& McAdams, 2004; Bursik, 1991; King, Scollon, Ramsey, \& Williams, 2000; Vaillant \& McCullough, 1987; Westenberg \& Block, 1993). In other words, people who think complexly about their lives are just as likely to be happy as unhappy.

Several narrative studies of life transitions have focused on maturity and/or well-being. Two narrative studies of life transitions have examined both. King et al. (2000) studied narratives about parents' finding out that their children had Down syndrome. The authors found that narratives with elements of accommodation correlated with ego development, whereas narratives with elements of foreshadowing, happy endings, and closure correlated with wellbeing. In another study, narratives of major life goals showed that goals oriented toward conceptual exploration corresponded primarily with ego development, whereas goals oriented toward intrinsic (vs. extrinsic) concerns corresponded primarily with well-being (Bauer \& McAdams, 2004). However, most research on life transitions has focused on either social-cognitive or social-emotional functions. On the social-cognitive side, Pancer, Pratt, Hunsberger, \& Gallant (2000) found that parents' complexity of thinking about parenthood increased after the child's birth, and that women with complex expectations adjusted better to parenthood. On the socialemotional side, Stewart and Vendewater (1999) found that the narrative expression of regret facilitated goal setting but that personal tendencies toward instrumentality and not ruminating were more directly related to actually making a life change. Bauer and Bonnano (2001b, 2001c) examined narrative and non-narrative measures longitudinally after the death of a spouse and found that an optimal balance of positive-to-negative self-evaluations, the integration of behaviors and characteristics, and a sense of selfefficacy each predicted successful adaptation over time. In all, these studies showed a direct link between narrative orientations and either social-cognitive maturity or social-emotional well-being. In

(regarding issues of happiness, depression, anxiety, etc.) about the self in a world of others? 
other words, the particular ways that people organize and create meaning (via personal narratives) in their life transitions have implications for particular strands of personality development.

Integrative themes and social-cognitive development. Theory and research on social-cognitive personality development emphasize two key mechanisms of development, one cognitive and one social: (1) the differentiation and integration of concepts and (2) social interactions and dialogue. Generally speaking, differentiation and integration spur cognitive development (Piaget, 1970), though cognitive development could only ensue in the ways and to the degree it does via social interaction (e.g., Vygotsky, 1978; Wertsch, 1991; Youniss, 1980). In terms of identity development (the subjective, personal dimension of personality development), identity development demands the differentiation of new perspectives on self and others, as well as the integration of these new perspectives into a new understanding of the self over time that enables the individual to act with greater capacities in an ever-widening range of contexts (Bauer \& Bonanno, 2001a). Damon and Hart (1988) outlined four stages of self-understanding development in youth, in which successive stages depended on the increasing ability to differentiate the perspectives of others and integrate them into a sense of self (a process that makes identity development possible). Kohlberg (1969) and Loevinger (1976) have shown how similar developmental processes operate in adulthood. In the present study, we identified narratives in which the individual emphasized these developmental concerns (i.e., the integration of new perspectives on the self and others). Such narratives were said to contain integrative themes; narratives without explicit description of social-cognitive concerns were considered "nonintegrative." 3 We expected that an emphasis on integrative themes would reflect higher levels of maturity, as measured by ego development (Hy \& Loevinger, 1996).

Intrinsic themes and social-emotional development. Theories of social-emotional personality development tend to focus on the individual's ability to adapt to the emotional demands of everyday

3. It is important to note that most approaches to narrative integration involve a focus on narrative structure, rather than narrative content or themes (e.g., McAdams, 1985; Woike, 1994). In contrast, our thematic approach focuses on the individual's perception of and importance placed on the integration of new perspectives into one's identity and worldview. 
life (e.g., Freud, 1953; Maslow, 1968). However, there is far less agreement on the mechanisms of social-emotional development than on the mechanisms of social-cognitive development. To start, our approach leans more toward the fostering of well-being than toward the cessation of suffering (see Ryff \& Singer, 1998; Seligman \& Csikszentmihalyi, 2000). With this in mind, we turned to the mechanisms of growth found in self-determination theory (SDT; Deci \& Ryan, 2000). SDT research has found that focusing on and acting upon intrinsically (vs. extrinsically) motivating values cultivate a sense of well-being, happiness, and life satisfaction (Kasser \& Ryan, 1996; Sheldon \& Kasser, 1995). Intrinsic values involve a concern for personal growth and happiness, meaningful relationships, and contributing to society. Extrinsic values involve a concern for money, status, and physical appearance. Research has found that intrinsically motivated activities and goals, relative to extrinsically motivated activities and goals, correspond to a variety of desirable phenomena (Deci \& Ryan, 2000). For example, people with intrinsically motivated goals have higher rates of goal attainment (Kasser, Ryan, Zax, \& Sameroff, 1995) and higher levels of well-being (Sheldon \& Kasser, 1995). Intrinsic goals have been shown to mediate the relationship between age and well-being (Bauer \& McAdams, 2004; Sheldon \& Kasser, 2001). In the present study, we studied intrinsically motivated memories rather than goals. We identified narratives that emphasized the perceived importance of intrinsic versus extrinsic (and other nonintrinsic) values as the source of personal meaning for an event or activity. It is important to note that, in contrast to most SDT research, we did not classify types of events as intrinsic or extrinsic but rather the personal meanings of those events as stated in the narratives (i.e., the reasons why the individual felt a memory was important) (see method section). We expected that people whose transition stories emphasized intrinsic themes would have higher levels of well-being (as measured by life satisfaction and personal well-being; Diener, Emmons, Larsen, \& Griffen, 1985; Ryff \& Keyes, 1995) as well as a greater sense that the transition had a positive impact on life). ${ }^{4}$

4. Measures of psychological health and well-being, unlike Loevinger's (1976) ego development, are generally not developmental in the sense of sequential stages. However, measures of health and well-being do assess the degree to which an individual has attained the desirable outcome of social-emotional development (as 


\section{Themes of Agentic and Communal Growth}

Personal stories tend to revolve around two themes, agency and communion (Bakan, 1966; McAdams, 1985). Personal stories can focus predominantly on agentic themes (e.g., emphasizing power) or on communal themes (e.g., emphasizing intimacy) - or both (e.g., emphasizing helping others) or neither (e.g., emphasizing escape; McAdams, 1993). Studies frequently show a relationship between communal themes and high levels of well-being, while the relationship between agentic themes and well-being is equivocal (McAdams, 1985). In the present study we extend the definitions of agency and communion in the direction of growth.

Agentic growth. McAdams (1985, 1993; McAdams, Hoffman, Mansfield, \& Day, 1996) has outlined four qualities of agency that appear in people's life stories: (1) impacting one's environment, (2) achieving valued outcomes, (3) self-mastery, and (4) status and prestige. Recently, we separated these qualities according to their orientation toward intrinsic versus extrinsic motivation (Bauer \& McAdams, 2000; Kasser \& Ryan, 1996; Sheldon \& Kasser, 1995). Of the four, the last one (status and prestige) deals primarily with extrinsically motivated concerns. We defined agentic growth in terms of the other three qualities of agency. Agentic-growth themes were coded in narrative episodes that emphasized a personally satisfying degree (from the point of view of the narrator) of attainment of these three qualities. In other words, agentic-growth themes were coded in narratives that emphasized having had a positive impact on others/ environment, having achieved some sought-after outcome, or for having attained some level of self-mastery. Themes of agency (as traditionally measured) tend not to correlate with well-being (McAdams, 1985). However, with the extrinsically oriented qualities of agency removed from our construct of agentic growth, we expected that agentic growth would correlate significantly with global well-being and the sense that the transition had a positive impact on one's life.

Communal growth. Qualities of communal themes include: (1) friendship and love, (2) dialogue and sharing, (3) connections with groups, society, humankind, or a god or higher power, and (4)

defined here). In this way, levels of social-cognitive maturity and social-emotional well-being represent the attainment or outcome of two broad facets of personality development. 
helping and caring for others (McAdams, 1985, 1993; McAdams et al., 1996). Such themes tend to be growth-oriented - at least when the quality in question has been more or less manifested in one's life. In other words, the relative fulfillment of love, dialogue, connections to something beyond the self, and caring all tend toward growth (at least of a social-emotional kind). Communal-growth themes were coded in narratives that emphasized one's having a personally satisfying degree (again from the perspective of the narrator) of one of these four qualities in life. Narrative themes of communion tend to correlate with well-being (McAdams, 1985). Therefore, we expected that themes of communal growth would correlate with well-being and would correlate with transition satisfaction.

\section{Stories of Career Versus Religion Transitions}

The themes or value orientations of transition stories do not arise in a vacuum. Specific types of major life changes involve specific social institutions, which have specific values and ideologies. These values are reflected in particular personal concerns that correspond to specific outcomes (Cicirelli, 1997; Finken \& Jacobs, 1996). For example, research on career transitions has focused heavily on the notion of person-environment fit (Holland, 1973; e.g., Oleski \& Subich, 1996; Rhodes \& Doering, 1993), where the focus tends to revolve around agentic concerns of the individual (e.g., the individual's competence, personality traits, and work interests). Research on religious change has also focused on the agentic search for a personally meaningful ideology (James, 1902; Pitt, 1991), but these ideologies and other aspects of religious conversion deal directly with communal concerns as well, for example, connections with families, groups, and a higher power (Paloutzian, Richardson, \& Rambo, 1999). Since life stories reflect the values of individuals as well as cultures (McAdams, 1993; Rosaldo, 1984), we expected that the transition stories of career and religion changers would reflect a relative emphasis on agentic and communal growth, respectively.

\section{Hypotheses and Other Inquiries}

Hypothesis 1. Integrative and intrinsic themes would differentiate the two forms of personality development. We predicted that integrative themes would correlate primarily with ego development, 
whereas intrinsic themes would correlate primarily with well-being. A recent study of narratives of major life goals found that exploratory goals (very similar in content to integrative themes in memories) correlated predominantly with ego development, whereas intrinsic goals correlated predominantly with well-being (Bauer \& McAdams, 2004).

Hypothesis 2. Themes of agentic and communal growth would each predict both well-being and the sense that the transition had a positive impact on life (measured by the Life Impact from Transition-LIFT - scale; adapted from Zinnbauer \& Pargament, 1998). However, given the facts that (1) having a positive impact is part of agentic-growth themes and (2) global measures of well-being have a strong history of correlations with communal themes, we predicted that agentic-growth themes would correlate more strongly than communal-growth themes with LIFT, whereas communal-growth themes would correlate more strongly than agentic-growth themes with well-being.

Hypothesis 3. Specific growth themes would reflect differences between career and religion changers. For reasons described earlier, we predicted that career changers would emphasize agentic themes, whereas religion changers would emphasize communal themes. We would further explore any differences between career and religion changers in the relations between growth themes and personality development.

Explorations. We were interested in two exploratory concerns: (1) Combinations of growth themes and (2) any themes that might correspond to a measure of the "good life," i.e., high levels of both maturity and well-being (King, 2001). First, we created four combined themes by crossing integrative and intrinsic themes with agentic- and communal-growth themes (see Figure 1). While coding, we realized that integrative and intrinsic themes each were expressed sometimes in terms of agentic growth and sometimes in terms of communal growth. So it seemed reasonable to explore combinations of these four themes in this manner. The combined themes were: integrative-agentic, integrative-communal, intrinsic-agentic, and intrinsic-communal. We then compared these combined themes with ego development and well-being. Finally, we looked for any themes that might have predicted high levels of both ego development and well-being, two qualities that have been said to indicate the good life (King, 2001; King et al., 2000). 


\begin{tabular}{|c|c|c|}
\hline & $\begin{array}{c}\text { AGENTIC-GROWTH } \\
\text { THEMES }\end{array}$ & $\begin{array}{c}\text { COMMUNAL-GROWTH } \\
\text { THEMES }\end{array}$ \\
\hline $\begin{array}{l}\text { INTEGRATIVE } \\
\text { THEMES }\end{array}$ & $\begin{array}{l}\text { Themes emphasizing an } \\
\text { increasing capacity for: } \\
\text { - conceptual self- } \\
\text { understanding } \\
\text { - organizing personal } \\
\text { concerns, goals, etc. }\end{array}$ & $\begin{array}{l}\text { Themes emphasizing an } \\
\text { increasing capacity for: } \\
\text { - conceptual understand- } \\
\text { ing of relationships } \\
\text { - moral reasoning }\end{array}$ \\
\hline $\begin{array}{l}\text { INTRINSIC } \\
\text { THEMES }\end{array}$ & $\begin{array}{l}\text { Themes emphasizing an } \\
\text { increasing capacity for: } \\
\text { - feeling good about } \\
\text { one's life and self } \\
\text { - acting/focusing on what } \\
\text { is personally important }\end{array}$ & $\begin{array}{l}\text { Themes emphasizing an } \\
\text { increasing capacity for: } \\
\text { - feeling good about } \\
\text { others/relationships } \\
\text { - caring for others; acting/ } \\
\text { focusing on fairness }\end{array}$ \\
\hline
\end{tabular}

Figure 1

Properties of personal growth in personal narratives. Integrative themes focus on the kinds of things that theoretically foster the ability to think more complexly about one's life, whereas intrinsic themes focus on the kinds of things that theoretically foster the ability to feel better about one's life. Themes of agentic growth and communal growth, respectively, focus on the more individual and the more collective aspects of personal growth. Since each episode in each transition story was coded for the presence of absence of each of the four themes, the combination of themes emerged in many episodes. By mapping the first two themes onto the second two, we created four combined categories of personal growth.

\section{METHOD}

\section{Participants and Procedure}

Sixty-seven adults responded to a Chicago newspaper ad that recruited participants for a study of life transitions in careers and religions. The sample included 40 career changers and 27 religion changers. The overall sample was $64 \%$ female and $28 \%$ minority in race and had a mean age of 41 years ( $S D=10$; range 25-73), a median household income between $\$ 30,000$ and $\$ 40,000$, and college degrees in $67 \%$ of the cases. Participants completed at their leisure a booklet containing narrative and non-narrative measures. 


\section{Writing the Transition Stories}

Participants wrote about their transition in 1-2-page narratives for each of six episodes or segments: (1) the decision to make the transition, (2) a turning point in making the change, (3) a conflict event, (4) an encounter with another person who played a role in the transition, (5) the projected future of the transition, and (6) a reflection on the relationship between the transition and personal identity. Each episode in the survey booklet included a paragraph that instructed participants on the particular topic of that episode. For most episodes, participants were instructed first to think about the topic (the decision, another person, etc.), then to pick a specific event in time (rather than a fuzzy or broader frame of time) that captured the essence of that topic, then to write about that event in terms of who, what, where, and when, and finally to write about how it made the participant think and feel, both during the event and in the present time.

\section{Overview of the Narrative Coding}

Each episode was given a code of " 1 " or " 0 " for the presence or absence of four themes: integrative, intrinsic, agentic growth, and communal growth. The total for each theme was tallied for each participant. Thus, a participant could have, at most, a score of 6 for intrinsic (or any other) themes, and at least a 0 . Two coders followed a strict protocol and were blind to other information about the participants.

\section{Coding for Integrative and Intrinsic Themes}

As mentioned earlier, integrative themes were derived from theory and research on social-cognitive development (e.g., Damon \& Hart, 1988). Integrative themes involved an emphasis in the narrative on the importance of learning, integrating, or otherwise coming to a new understanding about the self or others. A narrative did not need to give evidence that integration was found, only that integration was a concern; the mere searching for conceptual or ideological meaning constituted an integrative theme. Nonintegrative themes emphasized the experience or factual conditions of the situation but not whether one learned anything from it (or even tried to). Intrinsic themes were also about growth related to the self and others but were derived from theory and research on selfdetermination theory (Deci \& Ryan, 2000). Intrinsic themes involved an emphasis in the narrative on the importance of personal growth and happiness, meaningful relationships, and contributing to society. Nonintrinsic themes emphasized extrinsic concerns, such as the importance of money, status, approval, and physical appearance, as well as other 
nonintrinsic concerns, such as an emphasis on maintaining (rather than developing) one's health.

As for the coding procedure, coders first identified what event or activity or desire the episode was most centrally about, e.g., meeting with a friend to discuss the decision, taking a class that sparked an interest, needing to leave a bad situation, standing up for what one believes. These types of events were not the focus of the coding. Any one of these types of events could be coded for either integrative or nonintegrative themes and for either intrinsic or extrinsic themes. Rather, the target element of the narrative was the protagonist's predominant reason why that event was important. For example, in coding for intrinsic themes in decision episodes, the coder was to ask, "Did [the protagonist's] primary reason for deciding on the transition deal predominantly with personal growth, happiness, meaningful person-environment fit, fostering meaningful relationships with family or friends, or contributing to the development and welfare of the future generations or society (Kasser \& Ryan, 1996; Sheldon \& Kasser, 1995)?" It is important to note that many narratives expressed both growth and nongrowth orientations (i.e., both integrative and nonintegrative, both intrinsic and nonintrinsic), but individual episodes tended to emphasize a theme or not, much as larger stories generally emphasize particular themes (McAdams, 1993). Interrater kappas were $.53(86 \%$ agreement rate) for integrative themes and .67 (87\% agreement rate) for intrinsic themes. Discrepancies were resolved by discussion. Examples of narrative growth themes appear in the Appendix.

\section{Coding for Themes of Agentic and Communal Growth}

Narratives were further coded for concerns for agentic and communal growth. As mentioned earlier, these themes were similar to themes of agency and communion (McAdams, 1993; McAdams et al., 1996), except that agentic-growth themes did not involve concerns for status and dominance, and communal-growth themes focused on the attainment of communal ideals. Thus, agentic-growth themes involved a concern for cultivating personal competence and having a positive impact on the self and others (see Bauer \& McAdams, 2000), whereas communal-growth themes involved evidence of meaningful relationships and helping others. Interrater kappas were .64 ( $81 \%$ agreement rate) for agentic-growth themes and $.69(86 \%$ agreement rate) for communal-growth themes. Narrative examples of these themes appear in the Appendix.

\section{Combinations of Growth Themes}

We created four hybrid variables representing the number of episodes in which each participant had both integrative and agentic-growth themes, 
both integrative and communal-growth themes, both intrinsic and agentic-growth themes, and both intrinsic and communal-growth themes (see the content in the four quadrants of Figure 1). For example, an episode with both integrative and agentic-growth themes might emphasize issues of new understandings of oneself, whereas an episode with both integrative and communal-growth themes might emphasize issues of new understanding of a meaningful relationship. The total number of episodes with hybrid themes was tallied per person.

\section{Non-narrative measures}

Ego development. The Washington University Sentence Completion Test of Ego Development (ED; Hy \& Loevinger, 1996) asks participants to complete 18 sentence stems, for example, "When a child will not join in group activities..." "A man's job..." "My mother and I..." "A wife should..." and "Rules are...." Each item is first scored individually according to guidelines. Items are then aggregated into a total score that corresponds to particular stages in personality development. While Loevinger (1976) has noted the difficulty in defining a single phenomenon that characterizes this development, for the purposes of this study we view the ED stages as increasing capacities to think complexly about the self and others. Starting at Level 2 (with Level 1 being reserved for the presocial infant who as yet lacks an ego), the total scores are (2) Impulsive (characterized as passively dependent), (3) Self-protective (opportunistic), (4) Conformist (following rules), (5) Self-aware (concerned with fairness; consideration of rules), (6) Conscientious (self-evaluated standards), (7) Individualistic (respect for others' standards), (8) Autonomous (understanding of interdependence), (9) Integrated (reconciles conflicts within a broader identity). An advanced graduate student, well trained in the theory and measurement of ED, coded the responses. The ED scoring guidelines, which are self-instructive, have shown high levels of reliability and internal consistency (Loevinger \& Wessler, 1970).

Well-being. Participants completed two scales of well-being, the Satisfaction with Life Scale (SWLS; Diener et al., 1985) and Ryff's multidimensional scale of personal well-being (PWB; Ryff \& Keyes, 1995). The SWLS is a well-validated, simple, five-item measure of overall life satisfaction. The PWB measure is a well-validated, robust measure of six dimensions of well-being: autonomy, environmental mastery, personal growth, positive relationships, purpose in life, and self-acceptance. We used the mean PWB score, aggregated from the six separate scales, for all predictions in this study.

LIFT: Life impact from the transition. We adapted a scale measure originally used to assess the positive impact of a religious conversion on a person's life in various domains (Zinnbauer \& Pargament, 1995). We 
called this measure the Life Impact from Transition scale (LIFT). Participants were asked to rate on a 9-point scale how much for the better (9) or for the worse (1) the transition had affected nine domains in life, for example, one's "general outlook on life," "goals in life," "relationships with friend," "relationships with family," "life at work," "religious or spiritual life," and "day-to-day activities." Scores for each item were added to create a total LIFT score.

\section{RESULTS}

\section{Preliminary Findings}

Participants mentioned growth themes at the following rates: Integrative themes, $M=1.30, S D=1.48$; intrinsic themes, $M=2.42$, $S D=1.72$; agentic-growth themes, $M=3.18, S D=1.51$; communalgrowth themes, $M=3.07, S D=1.62$. The minimum frequency was 0 and the maximum was 6 (note: the number of episodes coded in transition stories) for all themes. Differences in these frequencies between career and religion changers are presented in the findings for Hypothesis 3. Career changers and religion changers did not differ significantly in levels of ED, PWB, or SWLS. However, religion changers did report a greater sense that the transition had a positive effect on their lives (LIFT), compared to career changers, $t(1,65)=$ $2.54, p=.01$.

Demographic variables did correlate significantly with personality variables. African Americans and Asian Americans scored significantly higher on LIFT, $t(1,65)=-2.79, p<.01$, than did European Americans. Income correlated significantly with integrative themes, $r=.27, p<.05$. Education correlated significantly with ED, $r=.24$, $p<.05$. Married participants had significantly more intrinsic themes, $r=.28, p<.05$, and communal-growth themes, $r=.40, p<.001$. Gender did not correlate significantly with any variable. Demographic variables did not significantly influence any of the results reported here.

\section{Hypothesis 1: Integrative and Intrinsic Themes}

ED did not correlate significantly with either PWB or SWLS ( $p>.10$; see Table 1). Integrative themes correlated significantly with intrinsic themes, $r=.52, p<.001$, yet the two themes mapped differentially onto ED and well-being. Integrative themes in the transition stories 
Table 1

Main Correlations

\begin{tabular}{|c|c|c|c|c|c|c|c|}
\hline Variable & ED & PWB & SWLS & LIFT & Integrative & Intrinsic & Agentic \\
\hline \multicolumn{8}{|l|}{ 1. ED } \\
\hline 2. PWB & .10 & & & & & & \\
\hline 3. SWLS & .17 & $.68^{* * * * *}$ & & & & & \\
\hline 4. LIFT & $-.23^{+}$ & $.40^{* * * * *}$ & $.33^{* * *}$ & & & & \\
\hline 5. Integrative & $.46^{* * * * *}$ & .19 & .17 & .04 & & & \\
\hline 6. Intrinsic & .16 & $.46^{* * * * *}$ & $.38 * *$ & $.25^{*}$ & $.52 * * * *$ & & \\
\hline 7. Agentic & .14 & $.24^{*}$ & .20 & $.46^{* * * * *}$ & $.47 * * * *$ & $.58 * * * *$ & \\
\hline 8. Communal & .15 & $.41 * * * *$ & $.39 * * *$ & $.28 *$ & $.30^{* * *}$ & $.60 * * * * *$ & $.30 * *$ \\
\hline
\end{tabular}

Note. $\mathrm{ED}=$ Ego Development. $\mathrm{PWB}=$ Personal Well-Being. SWLS $=$ Satisfaction with Life Scale. LIFT $=$ Life Impact from Transition scale. Variables 5-8 are narrative growth themes. When considering a Bonferroni adjustment of alpha at .002 , only correlations of magnitude .38 or higher are significant.

correlated significantly with ED, $r=.46, p<.001$, but not significantly with either PWB or SWLS, $p>.10$. Intrinsic themes correlated significantly with PWB, $r=.46, p<.001$, and SWLS, $r=.38, p<.01$, but not significantly with ED, $p>.10$. Thus, participants whose transition stories emphasized learning and integrating new perspectives on the self and others had higher levels of ED, whereas participants whose transition stories emphasized the importance of personal happiness, meaningful relationships, and contributing to society had higher levels of well-being. ${ }^{5}$

5. All the relationships between narrative themes and personality development were independent of the effects of Big-Five personality traits (John \& Srivastava, 1999). We found that narrative themes correlated significantly with some traits. None of the traits correlated significantly with ED, but neuroticism, extraversion, conscientiousness, and agreeableness correlated with PWB and SWLS. In regressions of well-being on narrative themes and relevant traits, we found that traits and stories played independent roles in explaining WB variance. Thus, consonant with the claim that traits and life stories may be related but are not hierarchically ordered (McAdams, 1995), we found that personal narratives played a unique role in understanding ED and well-being. 


\section{Hypothesis 2: Agentic- and Communal-Growth Themes}

Agentic-growth themes correlated significantly with PWB, $r=.24$, $p<.05$, but not with SWLS, $p>.10$ (see Table 1). Communal-growth themes correlated significantly with PWB, $r=.41, p<.001$, and SWLS, $r=.39, p<.001$. To measure whether agentic- or communal-growth themes were the more salient growth theme regarding well-being, we regressed PWB (and then SWLS) on both themes simultaneously. We found that communal-growth themes predicted PWB significantly, $\beta=.37, p<.001$, but agentic-growth themes did not, $p>.10$. Regressing SWLS on the two themes, we found that communal-growth themes predicted SWLS significantly, $\beta=.36$, $p<.001$, but agentic-growth themes did not, $p>.10$. We turn now to analyses with LIFT. LIFT correlated significantly with agenticgrowth themes, $r=.46, p<.001$, and communal-growth themes, $r=.28, p<.05$. To measure whether agentic- or communal-growth themes were the more salient growth theme regarding the sense that the transition had a positive impact on life, we regressed LIFT on both themes simultaneously. We found that agentic-growth themes predicted LIFT significantly, $\beta=.41, p<.001$, but communalgrowth themes did not, $p>.10$. Thus, while agentic-growth and communal-growth themes both correlated significantly with wellbeing and LIFT, agentic growth had more to do with the sense that one's transition had a positive impact on life, whereas communal growth had more to do with a global sense of well-being.

\section{Hypothesis 3: Themes in Career versus Religion Transition Stories}

Hypothesis 3 was that career and religion changers would place relatively more emphasis on agentic-growth and communal-growth themes, respectively. Religion changers were more likely than career changers to have integrative themes, $t(1,65)=2.62, p=.01$, and communal-growth themes, $t(1,65)=2.56, p=.01$ (see Table 2). However, religion changers and career changers were equally likely to have themes of intrinsic and agentic growth, $p s>.10$. Thus, half of Hypothesis 3 panned out: Themes of communal growth were more characteristic of religion-transition stories than career-transition stories, but themes of agentic growth were not more characteristic of career-transition stories than religion-transition stories. For career changers, agentic-growth themes did not correlate signifi- 
Table 2

Mean Frequencies of Narrative Themes for Career and Religion Changers

\begin{tabular}{|c|c|c|c|c|c|c|}
\hline \multirow[b]{2}{*}{ Variable } & \multicolumn{3}{|c|}{ Career Changers } & \multicolumn{3}{|c|}{ Religion Changers } \\
\hline & $M$ & $(S D)$ & Min-Max & $M$ & $(S D)$ & Min-Max \\
\hline Integrative Themes** & .92 & $(1.25)$ & $0-6$ & 1.85 & $(1.63)$ & $0-6$ \\
\hline Intrinsic Themes & 2.15 & $(1.75)$ & $0-6$ & 2.81 & $(1.62)$ & $0-6$ \\
\hline Agentic-growth Themes & 2.92 & $(1.61)$ & $0-6$ & 3.56 & $(1.28)$ & $0-6$ \\
\hline Communal-growth Themes*** & 2.68 & $(1.67)$ & $0-6$ & 3.67 & $(1.36)$ & $0-6$ \\
\hline
\end{tabular}

*** $p \leq .01$.

cantly with $\mathrm{PWB}, r=.10, p>.10$, and correlated only marginally with SWLS, $r=.30, p<.07$. Career changers' communal-growth themes correlated significantly with PWB, $r=.38, p<.05$, but not with SWLS, $r=.25, p>.10$. For religion changers, agentic-growth themes correlated significantly with PWB, $r=.42, p<.05$, but not with SWLS, $r=.02, p>.10$. Religion changers' communal-growth themes correlated significantly with PWB, $r=.44, p<.05$, and SWLS, $r=.60, p<.001$. Thus, themes of communal growth predicted well-being significantly for both career and religion changers, but themes of agentic growth predicted well-being significantly only for religion changers. Turning to LIFT, we found similar patterns for career and religion changers. For career changers, LIFT correlated with agentic-growth themes significantly, $r=.50, p<.001$ but not with communal-growth themes, $r=.26, p>.10$. For religion changers, LIFT correlated marginally significantly with agenticgrowth themes, $r=.33, p<.10$, but not with communal-growth themes, $r=.12, p>.10$.

\section{Explorations: Combinations of Growth Themes}

We next considered correlations with the four hybrid variables (see Figure 1). ED correlated significantly with both integrative-agentic themes, $r=.42, p<.001$, and integrative-communal themes, $r=.32$, $p<.01$, but not with either intrinsic-agentic or intrinsic-communal themes, $p \mathrm{~s}>.10$. A regression of ED on integrative-agentic themes and integrative-communal themes simultaneously revealed that only the integrative-agentic themes predicted ED significantly, $\beta=.45$, 
$p<.05$. PWB correlated significantly with intrinsic-agentic themes, $r=.38, p<.01$, and intrinsic-communal themes, $r=.44, p<.001$, as well as with integrative-communal themes, $r=.25, p<.05$, but not with integrative-agentic themes, $p>.10$. SWLS correlated significantly with intrinsic-agentic themes, $r=.32, p<.01$, and intrinsiccommunal themes, $r=.44, p<.001$, as well as with integrativecommunal themes, $r=.26, p<.05$, but not with integrative-agentic themes, $p>.10$. A regression of PWB on intrinsic-agentic themes and intrinsic-communal themes simultaneously revealed that intrinsic-communal themes predicted PWB significantly, $\beta=.41, p<.05$, but intrinsic-agentic themes did not, $p>.10$. A regression of SWLS on intrinsic-agentic themes and intrinsic-communal themes simultaneously revealed that intrinsic-communal themes predicted PWB significantly, $\beta=.54, p<.01$, but intrinsic-agentic themes did not, $p>.10$. Overall, these findings suggested that stories geared toward new understandings within one's agentic growth was especially predictive of high ED, while stories geared toward intrinsic concerns within one's communal growth were especially predictive of high well-being. Finally, it is noteworthy that among the four combined themes, only integrative-communal themes correlated significantly with both ED and well-being. Thus, participants whose transition stories emphasized arriving at new understandings of communal growth had higher levels of maturity and well-being.

\section{DISCUSSION}

This study examined how specific themes of personal growth in stories of people's life transitions corresponded to specific measures of personality development. We examined four such themes: integrative, intrinsic, agentic growth, and communal growth. We found that the first two themes held differential relationships with measures of social-cognitive maturity and social-emotional well-being. We found that the second two themes (agentic growth and communal growth) held differential relationships with transition-specific satisfaction and global well-being. Finally, we found differences between career and religion changers in their interpretations of agentic growth and communal growth and in how these related to wellbeing. These findings highlight specific relationships between narrative thinking and personality development, suggest how social 
institutions exert an influence over the value orientations of personal narratives, further an understanding of the role of personal growth in narrative meaning-making, and have implications for the study of intentional self-development.

\section{Integrative and Intrinsic Themes}

We found that the social-cognitive and social-emotional themescalled integrative and intrinsic themes - corresponded differentially to ED and WB. Previous narrative research on these themes in major life goals (Bauer \& McAdams, 2004), as well as with similar constructs in autobiographical memories (King et al., 2000), suggested that this would be the case. In general, social-cognitive maturity and social-emotional well-being do not correlate significantly and tend to map onto different constructs of personality and development (e.g., King et al., 2000; Westenberg \& Block, 1993). Together, these findings suggest, among other things, that the specific ways people think about and plan their lives have implications for specific kinds of personal growth and personality development-notably intentional self-development (Brandtstadter et al., 1999). For example, if one wishes to be happier, but in reflecting on the past and planning the future, emphasizes the importance of gaining the approval of others, then happiness is not likely to ensue as a result. (Or, if one wishes to make a lot of money but instead spends all his time thinking about personal growth and how to foster meaningful relationships, the money might not follow.) Of course, determining such factors prospectively demands a longitudinal design, for which there is preliminary support, at least regarding the predictable benefits of focusing on intrinsic versus extrinsic concerns (Sheldon, Kasser, Smith, \& Share, 2002). As the study stands, we found that maturity and well-being coincide with specific styles of growth-oriented narratives.

Our theoretical reason for these findings (as well as the findings with agentic and communal growth, discussed below) starts with the notion that people are likely to emphasize and talk more about the kinds of things that are important to them (McAdams, 1993). Similarly, the themes that arise frequently in an individual's narratives of self-defining memories are likely to reflect the types of things the individual thinks are important and the types of things on which the individual is exerting energy in everyday life. Development 
emerges from action and making sense of it (Piaget, 1970; Wertsch, 1991), such that the type of development that ensues depends on the type of actions done and the type of meanings ascribed to them. To the degree that people are thinking about and enacting the mechanisms or kinds of things that foster a particular kind of personality development (as the differentiation and integration of new perspectives on the self and others fosters social-cognitive maturity), that development will ensue. Of course, development is not that simple (where proportions of concern and effort = proportions of developmental attainment); development depends not only on personal intentions but on impersonal social and biological forces as well (Lerner \& Walls, 1999). However, to the degree that intention and action play a role in development, a similar scenario should emerge. Reflecting these intentions and processes, specific themes that are emphasized in stories about events like life transitions should reflect specific kinds of personality development.

\section{Agentic- and Communal-Growth Themes}

We found that themes of agentic and communal growth, both framed in terms of social-emotional growth, corresponded to different measures of personal satisfaction. People whose stories emphasized agentic growth were more likely to think that their transition had a positive impact on their lives, whereas people whose stories emphasized communal growth were more likely to report high levels of well-being in general. By way of explaining these results, we note that part of the definition of agentic growth (and agentic themes more generally; McAdams et al., 1996) is the sense that one exerts an influence in one's environment. In addition, communal themes historically hold stronger ties to well-being than do agentic themes - a finding that held even when considering only the intrinsically motivated qualities of agency. These findings suggest that placing importance on meaningful relationships in one's personal narratives plays a significant role in global well-being, while placing importance on one's growth as an individual plays a significant role in evaluating life changes as having a positive impact on life.

\section{Career Changers Versus Religion Changers}

We made predictions regarding the differential use of agentic- and communal-growth themes by career changers versus religion chan- 
gers, but not regarding the use of integrative and intrinsic themes. So we begin with the former. Religion changers expressed more themes of communal growth than did career changers. We expected this to be the case since religious institutions emphasize the role of communal concerns (Paloutzian, 1996), whereas work environments tend to support and reward the virtues of agentic concerns (e.g., Kirk, 1989). However, career changers did not have more agenticgrowth themes than religion changers. Perhaps this finding has its roots in the fact that religion changes often demand a good deal of agentic initiative and commitment (Rambo, 1993) in addition to focusing on the welfare of others (e.g., generativity demands a sense of personal agency; McAdams et al., 1998). Interestingly, themes of agentic growth did not correlate significantly with wellbeing for career changers, but did so for religion changers. In contrast, themes of communal growth correlated with well-being for both career and religion changers. Overall, these findings point to counterintuitive - or at least seldom-considered - conclusions: First, career changers who focused on other people in their transition stories (e.g., changing one's career to create a better family life; the importance of interpersonal relationships at work) were happier than those who focused on more individualistic concerns like personal achievement. This was true despite the emphasis placed on agentic concerns by both researchers and work institutions. Second, religion changers who focused on things like having an impact on one's environment and on self-mastery in their transition stories (and not just on things like love and one's connection to other people, to a religion, or to higher powers) had higher levels of wellbeing.

Finally, religion changers mentioned integrative themes more frequently than did career changers, perhaps reflecting the fact that religious institutions emphasize the role of ideological meaning making (Stromberg, 1990), whereas work institutions typically encourage their individuals to focus on more pragmatic concerns. However, the stories of career and religion transitions had the same frequencies of intrinsic themes. This finding is consonant with the fact that research on both career and religion changes has emphasized the importance of intrinsic concerns like personal growth (Kanchier \& Unruh, 1989; Kasser \& Ryan, 1996; Oleski \& Subich, 1996; Paloutzian et al., 1999; Rambo, 1993). 


\section{Growth Themes and the Good Life}

King (2001) has identified maturity and happiness as two facets of "the good life." As noted earlier, ED and well-being tend not to correlate in adulthood, and individual personality constructs tend to map onto one or the other but not both (e.g., King et al., 2000; see also the correlates of meaning and happiness in McGregor \& Little, 1998; for an exception see the relation of generativity to ED and well-being in de St. Aubin \& McAdams, 1995). So most people, according to King's definition, are not living the good life. Yet a sizable minority of people do live the good life; these are the mature, happy people, the ones in this study with high levels of both ED and well-being. We found a couple of narrative patterns that characterized participants who had high levels of both ED and well-being. First, they emphasized integrative and intrinsic themes in their transition stories. In other words, mature, happy people focused on what they learned about personally meaningful concerns - not just on anything they learned and not just on the experience of something personally meaningful. Second, people who appeared to be living the good life emphasized both integrative and communalgrowth themes. In other words, a unique quality of participants who appeared to be living the good life was their emphasis on the importance of gaining new perspectives on meaningful relationships amid their transition - not just experiencing the feelings of close relationships, and not just learning more or feeling better about oneself. In this study, communal themes were often intrinsic themes as well, as hinted by their high correlation. Thus these data overall suggested the following scenario: Mature, happy people, when telling stories of their life transitions, focused on what they learned about personally meaningful concerns - particularly, what they learned about their close relationships. In contrast, focusing on what one learned about agentic concens predicted only maturity, while focusing only on meaningful relationships, but not on what one learned about them, predicted only well-being.

\section{Limitations and Distinctions}

We wish to caution against interpreting these results (1) in a causal fashion and (2) as objective data. These data were correlational, and we attempted not to phrase the findings and their interpretations in a causal manner. However, the language of statistical procedures such 
as regression models (with their "effects" and "X predicts Y") often sounds causal. Though we phrased most findings by listing the narrative themes first and then their relationship with personalitydevelopment variables, we did not imply that one caused the other. Of course the causal order could well be the reverse of that direction: For example, high levels of ego development could well lead one to look for the conceptual lessons in a significant life event. Or else, another phenomenon could well underlie both one's narrative themes and personality development.

Next, we wish to consider factors of bias. First, since the study used volunteer participants, it is likely to have had a selection bias toward people who had more positive views of their transition (though there was a range of this). Thus, there are limitations on the capacity to generalize this sample of life transitions to its general population. Second, this study may well be subject to self-report biases. However, self-report biases come in many forms. The common one-that what people report about their lives does not reflect how their lives actually operate - is for this study not a problem but rather the phenomenon of interest. We were precisely interested in how certain kinds of interpretations (in narratives) correspond to other kinds of interpretations (in personality development). In general we think that interpretations of significant life events - coming as they do with all sorts of personal biases - have implications for how people plan their actions and their life course. However, participants may have provided interpretations of their transition story that do not conform to the interpretations they typically make outside of this exercise. This kind of bias would present a problem for claiming that their transition stories (in everyday life) relate to personality development. However, we note that participants probably would have had to make alternative interpretations consistently over the course of the transition story in order for this kind of bias to influence the results.

As a final note, the mere fact that a variable is subjective rather than objective in nature does not make the variable less of a factor in the everyday world of thoughts, feelings, and behaviors. Similarly, subjective phenomena are no less valid than objective phenomena as a target of systematic, scientific interest. Subjective variables are simply, on average, more difficult to define by virtue of their being less apparent. Should science be afraid of such difficulties and therefore stick to that which is defined more easily (both conceptually and in 
terms of time and money)? We think not. In the end, the limitation of these self-report data is simply the reverse of the limitation of more objective data. Here, we can speak only of the individual's subjective experience; there, we can speak only of appearances.

\section{CONCLUSION}

The main message from this study is that specific ways of interpreting one's life transition correspond to specific forms of personality development. People whose transition stories emphasized learning new things had higher levels of social-cognitive maturity, whereas people whose stories emphasized intrinsically meaningful concerns had higher levels of well-being. Also, people whose stories emphasized an agentic, individually based form of growth were more satisfied that their transition had a positive impact on their lives, whereas people whose stories emphasized communal growth had higher levels of global well-being. Religion changers were more likely than career changers to emphasize communal growth in their stories, but communal concerns played a more dominant role than agentic concerns in career changers' well-being, despite the emphasis placed on agentic concerns in career research. Finally, participants who emphasized both integrative and communal themes - that is, those who stressed the importance of learning something about relationships - appeared to be living the good life, defined as a life rich in meaning and happiness. While the present study was correlational and retrospective in design, we hope that narrative work on topics of personal growth can help uncover the patterns in people's intentions and life interpretations that will contribute to a better understanding of the processes of intentional self-development (Brandtstadter et al., 1999; Lerner \& Walls, 1999).

\section{REFERENCES}

Bakan, D. (1966). The duality of human existence: Isolation and communion in Western man. Boston: Beacon Press.

Bauer, J. J., \& Bonanno, G. A. (2001a). Continuity amid discontinuity: Bridging one's past and present in stories of conjugal bereavement. Narrative Inquiry, 11, 123-158.

Bauer, J. J., \& Bonanno, G. A. (2001b). Doing and being well (for the most part): Adaptive patterns of narrative self-evaluation during bereavement. Journal of Personality, 69, 45-482. 
Bauer, J. J., \& Bonanno, G. A. (2001c). I can, I do, I am: The narrative differentiation of self-efficacy and other self-evaluations while adapting to bereavement. Journal of Research in Personality, 35, 424-448.

Bauer, J. J., \& McAdams, D. P. (2000). Competence, relatedness, and autonomy in life stories. Psychological Inquiry, 11, 276-279.

Bauer, J. J., \& McAdams, D. P. (2004). Growth goals, maturity, and well-being. Developmental Psychology, 40, 114-127.

Brandtstadter, J., Wentura, D., \& Rothermund, K. (1999). Intentional selfdevelopment through adulthood and later life: Tenacious pursuit and flexible adjustment of goals. In J. Brandtstadter \& R. M. Lerner (Eds.), Action and selfdevelopment: Theory and research through the life span (pp. 373-400). Thousand Oaks, CA: Sage.

Bursik, K. (1991). Adaptation to divorce and ego development in adult women. Journal of Personality and Social Psychology, 60, 300-306.

Cantor, N., \& Kihlstrom, J. F. (1987). Personality and social intelligence. Englewood Cliffs, NJ: Prentice-Hall.

Cicirelli, V. G. (1997). Relationship of psychosocial and background variables to older adults' end-of-life decisions. Psychology and Aging, 12, 72-83.

Damon, W., \& Hart, D. (1988). Self-understanding in childhood and adolescence. Cambridge: Cambridge University Press.

Deci, E. L., \& Ryan, R. M. (2000). The "what" and "why" of goal pursuits: Human needs and the self-determination of behavior. Psychological Inquiry, 11, 277-268.

de St. Aubin, E, \& McAdams, D. P. (1995). The relations of generative concern and generative action to personality traits, satisfaction/happiness with life, and ego development. Journal of Adult Development, 2, 99-112.

Diener, E., Emmons, R. A., Larson, R. J., \& Griffen, S. (1985). The satisfaction with life scale. Journal of Personality Assessment, 49, 71-75.

Erikson, E. H. (1950/1994). Childhood and society. New York: Norton.

Finken, L. L., \& Jacobs, J. E. (1996). Consultant choice across decisions: Are abortion decisions different? Journal of Adolescent Research, 11, 235-260.

Flanagan, O. (1991). Varieties of moral personality: Ethics and psychological realism. Cambridge, MA: Harvard University Press.

Freud, S. (1953). The standard edition of the complete psychological works (J. Strachey Ed. and Trans.). London: Hogarth Press.

Greenberg, J. R., \& Mitchell, S. A. (1983). Object relations in psychoanalytic theory. Cambridge, MA: Harvard University Press.

Gollwitzer, P. M., Bayer, U., Scherer, M., \& Seifert, A. E. (1999). A motivationalvolitional perspective on identity development. In J. Brandtstadter \& R. M. Lerner (Eds.), Action and self-development: Theory and research through the life span (pp. 283-314). Thousand Oaks, CA: Sage.

Hy, L. X., \& Loevinger, J. (1996). Measuring ego development, 2nd ed. Mahwah, NJ: Lawrence Erlbaum.

Holland, J. L. (1973). Making vocational choices: A theory of careers. Englewood Cliffs, NJ: Prentice-Hall.

James, W. (1902). The varieties of religious experience. New York: Library of America. 
John, O. P., \& Srivastava, S. (1999). The Big Five trait taxonomy: History, measurement, and theoretical perspectives. In L. A. Pervin \& O. P. John (Eds.), Handbook of personality: Theory \& research (2nd ed). New York: Guilford Press.

Kanchier, C., \& Unruh, W. R. (1989). Factors influencing career change. International Journal for the Advancement of Counseling, 12, 309-321.

Kasser, T., \& Ryan, R. M. (1996). Further examining the American dream: Differential correlates of intrinsic and extrinsic goals. Personality and Social Psychology Bulletin, 22, 80-87.

Kasser, T., Ryan, R. M., Zax, M., \& Sameroff, A. J. (1995). The relations of maternal and social environments to late adolescents' materialistic and prosocial values. Developmental Psychology, 31, 907-914.

King, L. A. (2001). The hard road to the good life: The happy, mature person. Journal of Humanistic Psychology, 41, 51-72.

King, L. A., Scollon, C. K., Ramsey, C., \& Williams, T. (2000). Stories of life transition: Subjective well-being and ego development in parents of children with Down Syndrome. Journal of Research in Personality, 34, 509-536.

Kirk, J. J. (1989). Job satisfaction among Type C career changers. Journal of Employment Counseling, 26, 161-168.

Kohlberg, L. (1969). State and sequence: the cognitive-developmental approach to socialization. In D. A. Goslin (Ed.), Handbook of socialization theory and research (pp. 347-480). Skokie, IL: Rand McNally.

Lerner, R. M., \& Walls, T. (1999). Revisiting Individuals as producers of their environment: From dynamic interactionalism to developmental systems. In J. Brandtstadter \& R. M. Lerner (Eds.), Action and self-development: Theory and research through the life span (pp. 3-36). Thousand Oaks, CA: Sage.

Loevinger, J. (1976). Ego development. San Francisco: Jossey-Bass.

Loevinger, J., \& Wessler, R. (1970). Measuring ego development: Vol. 1. Construction and use of a sentence completion test. San Francisco: Jossey-Bass.

Maslow, A. H. (1968). Toward a psychology of being. New York: Van Nostrand Reinhold.

McAdams, D. P. (1985). Power, intimacy, and the life story. New York: Guildford.

McAdams, D. P. (1993). The stories we live by: Personal myths and the making of the self. New York: William Morrow.

McAdams, D. P. (1995). What do we know when we know a person? Journal of Personality, 63, 365-396.

McAdams, D. P., Hart, H. M., \& Maruna, S. (1998). The anatomy of generativity. In D. P. McAdams \& E. de St. Aubin (Eds.), Generativity and adult development: How and why we care for the next generation (pp. 7-44). Washington, DC: American Psychological Association.

McAdams, D. P., Hoffman, B. J., Mansfield, E. D., \& Day, R. (1996). Themes of agency and communion in significant autobiographical scenes. Journal of Personality, 64, 339-377.

McAdams, D. P., Josselson, R., \& Lieblich, A. (2001). Turns in the road: Narrative studies of lives in transition. Washington, DC: American Psychological Association. 
McGregor, I., \& Little, B. R. (1998). Personal projects, happiness, and meaning: On doing well and being yourself. Journal of Personality and Social Psychology, 74, 494-512.

Oleski, D., \& Subich, L. M. (1996). Congruence and career change in employed adults. Journal of Vocational Behavior, 49, 221-229.

Paloutzian, R. F. (1996). Invitation to the psychology of religion. Boston: Allyn and Bacon.

Paloutzian, R. F., Richardson, J. T., \& Rambo, L. R. (1999). Religious conversion and personality change. Journal of Personality, 67, 1047-1079.

Pancer, S. M., Pratt, M., Hunsberger, B., \& Gallant, M. (2000). Thinking ahead: Complexity of expectations and the transition to parenthood. Journal of Personality, 68, 253-280.

Piaget, J. (1970). Piaget's theory. In P. Mussen (Ed.), Carmichael's manual of child psychology (pp. 703-732). New York: John Wiley.

Pitt, J. E. (1991). Why people convert: A balance theoretical approach to religious conversion. Pastoral Psychology, 39, 171-183.

Rambo, L. R. (1993). Understanding religious conversion. New Haven, CT: Yale University.

Rhodes, S. R., \& Doering, M. M. (1993). Intention to change careers: Determinants and processes. The Career Development Quarterly, 42, 76-92.

Rosaldo, M. (1984). Toward an anthropology of self and feeling. In R. Shweder \& R. LeVine (Ed.), Culture theory (pp. 137-157). New York: Cambridge University.

Ryff, C. D., \& Keyes, C. L. M. (1995). The structure of psychological well-being revisited. Journal of Personality and Social Psychology, 69, 719-727.

Ryff, C. D., \& Singer, B. (1998). The contours of positive health. Psychological Inquiry, 9, 1-28.

Seligman, M. E. P., \& Csikszentmihalyi, M. (2000). Positive psychology: An introduction. American Psychologist, 55, 5-14.

Sheldon, K. M., \& Kasser, T. (1995). Coherence and congruence: Two aspects of personality integration. Journal of Personality and Social Psychology, 68, 531-543.

Sheldon, K. M., \& Kasser, T. (2001). Getting older, getting better? Personal strivings and psychosocial maturity across the life-span. Developmental Psychology, 34, 491-501.

Sheldon, K. M., Kasser, T., Smith, K., \& Share, T. (2002). Personal goals and psychological growth: Testing an intervention to enhance goal attainment and personality integration. Journal of Personality, 70, 5-31.

Stewart, A. J., \& Vandewater, E. A. (1999). "If I Had It to Do Over Again...": Midlife Review, Midcourse Corrections, and Women's Well-Being in Midlife. Journal of Personality and Social Psychology, 76, 270-283.

Stromberg, P. G. (1990). Ideological language in the transformation of identity. American Anthropologist, 92, 42-56.

Vaillant, G. E., \& McCullough, L. (1987). The Washington University Sentence Completion Test compared with other measures of adult ego development. American Journal of Psychiatry, 144, 1189-1194. 
Vygotsky, L. S. (1978). Mind in society: The development of higher psychological processes. Cambridge, MA: Harvard University Press.

Wertsch, J. V. (1991). Voices of the mind: A sociocultural approach to mediated action. Cambridge, MA: Harvard University Press.

Westenberg, P. M., \& Block, J. (1993). Ego development and individual differences in personality. Journal of Personality and Social Psychology, 65, 792-800.

Woike, B. A. (1994). The use of differentiation and integration processes: Empirical studies of "separate" and "connected" ways of thinking. Journal of Personality and Social Psychology, 67, 142-150.

Youniss, J. (1980). Parents and peers in social development: A Sullivan-Piaget perspective. Chicago: University of Chicago.

Zinnbauer, B. J., \& Pargament, K. I. (1998). Spiritual conversion: A study of religious change among college students. Journal for the Scientific Study of Religion, 37, 161-180.

\section{APPENDIX}

Integrative and Intrinsic Themes

Integrative and Intrinsic. "We took time to discuss issues and thoughts that didn't normally present themselves in our daily lives. I learned more about [my husband] and his spirituality. This really strengthened our marriage, as my feelings for him became deeper and more caring." This narrative focused on gaining new understandings of self, another, and a relationship.

Integrative and Extrinsic. "I had grown up in a more institutional church that, despite its rules and regulations, was comfortable like an old sweatshirt. I had to get used to the people without completely losing my former identity." This narrative focused on issues of integrating the new environment while still maintaining continuity with the past. However, the reasons for doing so were grounded in the fact that the person "had to" convert upon getting married from a religion with which he had been comfortable.

Non-Integrative and Intrinsic. "There were a lot of conflicting views from family.... There were always arguments that surfaced about my converting. It was said that I was brainwashed [and] around bad influences. Even my aunt [who had converted along with the participant and the participant's spouse] converted back... which I'm not gonna consider because I'm happy with who I am and the choice we made thus far." This narrative described diverging viewpoints but no desire to integrate them. However, the narrative did 
express self-determination and satisfaction with doing what one deeply desired.

Non-Integrative and Extrinsic. "My realization was a gradual process defined in negative terms. I wasn't sure what I wanted to do, but as time passed, I knew more and more precisely what I did not want to do.... I hit a saturation point, and I left.... Then I received a job offer, which I accepted for lack of anything better to do." This narrative focused exclusively on the experiences of the situation, rather than on the concern for integrating new perspectives or conditions into a sense of personal identity. This narrative also emphasized the notion of "falling into" a career, a transition that lacked a sense of self-determination.

\section{Agentic- and Communal-Growth Themes}

Agentic and Communal. "During a staff rotation in pediatrics... I knew that no matter how much I held him, sang to him, tried to teach him, that I was too late for this little human being. Instances of neglect and abuse in children, which were more frequent than you'd ever imagine, began to create a feeling in me that I wanted to be there early enough to make a difference." This narrative centered on a concern for generativity (Erikson, 1950; McAdams, Hart, \& Maruna, 1998) in a way that emphasized both the agentic concern for having an impact on others and the communal concern for younger generations.

Agentic but not Communal. "I had grown accustomed to making a couple hundred thousand dollars a year and being able to afford whatever I wanted to buy.... I also knew that the social work profession paid significantly less.... I approached the conflict with much trepidation.... Today, I have resolved the conflict. I am much more content and able to appreciate the smaller things with less money." This narrative conveyed in a couple ways a sense of personal ability, without reference to other people or relationships. Communal but not Agentic. "I knew how important her religion was to her and that if I wished to love her completely, I would have to accept that part of her for us and our future family. She was the more religious of the two of us, and I knew I would be the one to eventually convert." This narrative emphasized the importance of love and relationships, but did not involve the sense of competence or making an impact. 
Neither Agentic nor Communal. "There was a long time when I was bored with my job and knew it didn't require any brain cells.... The enabling moment was an ad in the newspaper for an entry-level part time help-desk position. Because I could keep my real job and try out this new career at the same time, I told myself that if I didn't like it I'd just quit." This narrative conveyed no sense of personal competence, having an impact on others, or connection to others. 
This document is a scanned copy of a printed document. No warranty is given about the accuracy of the copy. Users should refer to the original published version of the material. 